\title{
Azobenzene-Linked Porphyrin-Fullerene Dyads
}

\author{
David I. Schuster, ${ }^{a}{ }^{a}$ Ke Li, ${ }^{* a, b}$ Dirk M. Guldi, ${ }^{c}$ Amit \\ Palker, ${ }^{\mathrm{d}}$ Luis Echegoyen, ${ }^{\mathrm{d}}$ Christopher Stanisky, ${ }^{\mathrm{e}} \mathbf{R}$. \\ James Cross, ${ }^{e}$ Marja Niemi ${ }^{f}$, Nikolai V. Tkachenko ${ }^{f}$ \\ and Helge Lemmetyinen ${ }^{f}$
}

${ }^{a}$ Chemistry Department, New York University, New York City, NY 10003, USA

${ }^{b}$ Current address: Central Research and Development, E. I. DuPont de Nemours and Co.,

Experimental Station, Wilmington DE 19880

${ }^{c}$ Institute for Physical Chemistry, University of Erlangen, Erlangen 91085, Germany

${ }^{d}$ Chemsitry Department, Clemson University, Clemson, SC, 29634, USA

e Department of Chemistry, Yale University, New Haven, CT 06520, USA

f Institute of Materials Chemistry, Tampere Institute of Technology, 33101 Tampere, Finland

Email Addresses: david.schuster@nyu.edu

\section{Contents}

Figure S1. Cyclic voltammogram (CV) of compound 3

Figure S2. Differential Pulse Voltammetry (DPV) of compound 3

Figure S3. CV of compound $\mathbf{4 b}$

Figure S4. DPV of compound $\mathbf{4 b}$

Figure S5. CV of compound $\mathbf{5 b}$

Figure S6. DPV of compound $\mathbf{5 b}$

Figure S7. CV of compound $\mathbf{4 a}$

Figure S8. CV of compound 5a

Figure S9. Time-resolved fluorescence decay of the $\mathrm{ZnP}$ reference and $\mathrm{Me}-\mathrm{H}_{2} \mathrm{P}-\mathrm{C}_{60} 4 \mathbf{a}$ in toluene 
Figure S10. Differential absorption spectrum (visible) upon femtosecond flash photolysis $(387 \mathrm{~nm})$ of ZnP reference in nitrogen-saturated benzonitrile and time-absorption profile at $750 \mathrm{~nm}$

Figure S11. Differential absorption spectrum (visible) upon femtosecond flash photolysis $\left(387 \mathrm{~nm}\right.$ ) of $\mathrm{Me}-\mathrm{H}_{2} \mathrm{P}-\mathrm{C}_{60} \mathbf{4 a}$ in nitrogen-saturated benzonitrile at room temperature, and time-absorption profile at $420 \mathrm{~nm}$

Figure S12. Differential absorption spectrum (visible) upon femtosecond flash photolysis $(387 \mathrm{~nm})$ of Me-ZnP-C 60 5a in nitrogen-saturated benzonitrile at room temperature, and time-absorption profile at $480 \mathrm{~nm}$

Figure S13. Time-absorption profile at $1000 \mathrm{~nm}$ monitoring the $\mathrm{C}_{60}{ }^{-}$decay dynamics of dyad $\mathbf{5 b}$ following $532 \mathrm{~nm}$ excitation in nitrogen-saturated THF

Figure S14. Time-absorption profile at $1000 \mathrm{~nm}$ monitoring the $\mathrm{C}_{60}{ }^{-}$decay dynamics of dyad 4a following $532 \mathrm{~nm}$ excitation in nitrogen-saturated THF.

Figure S15. ${ }^{3} \mathrm{He}$ NMR spectrum of dyad $\mathbf{4 b}$

Figure S16. ${ }^{1} \mathrm{H}$ NMR spectrum of $3 a\left(\mathrm{R}=\mathrm{R}_{1}\right)$

Figure S17. ${ }^{1} \mathrm{H}$ NMR spectrum of 3a

Figure S18. ${ }^{1} \mathrm{H}$ NMR spectrum of $\mathbf{3 b}$

Figure S19. ${ }^{1} \mathrm{H}$ NMR spectrum of $\mathbf{4 a}$

Figure S20. ${ }^{1} \mathrm{H}$ NMR spectrum of $\mathbf{4 b}$

Figure S21. ${ }^{1} \mathrm{H}$ NMR spectrum of $\mathbf{5 a}$

Figure S22. ${ }^{1} \mathrm{H}$ NMR spectrum of $\mathbf{5 b}$. 


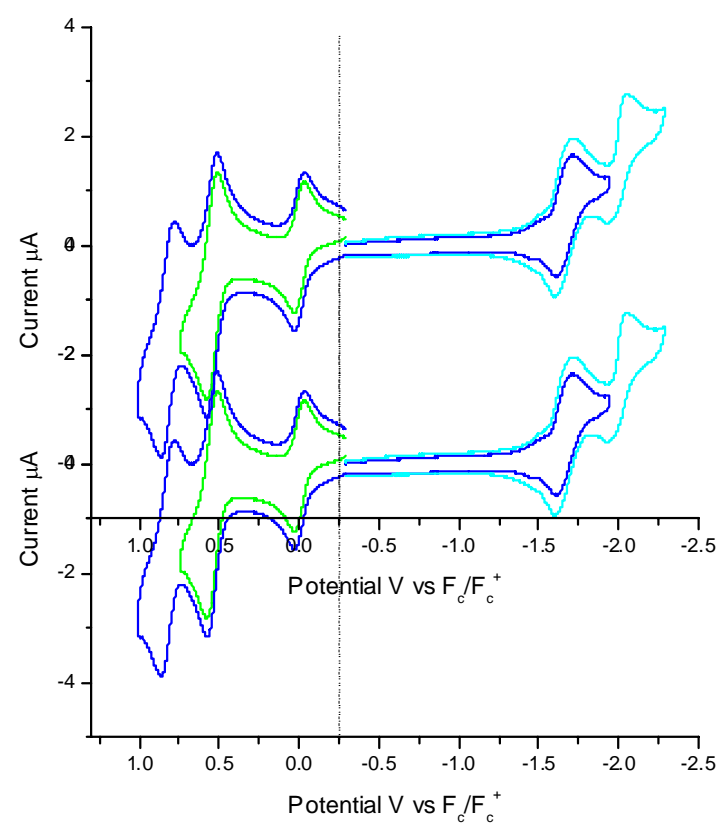

Figure S1.

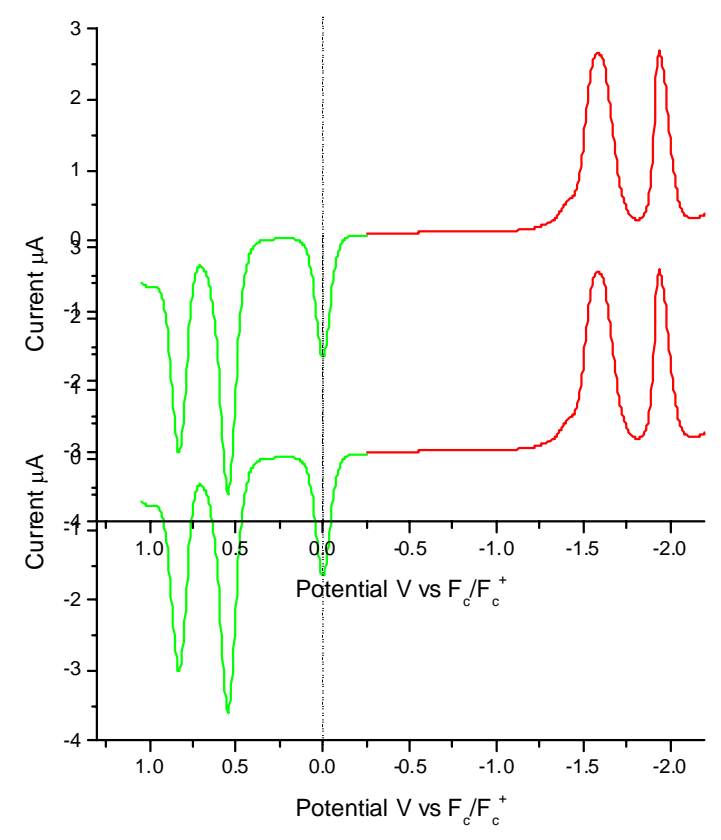

Figure S2.

Figure S1. Cyclic voltammogram (CV) of compound 3

Figure S2. Differential Pulse Voltammetry (DPV) of compound 3

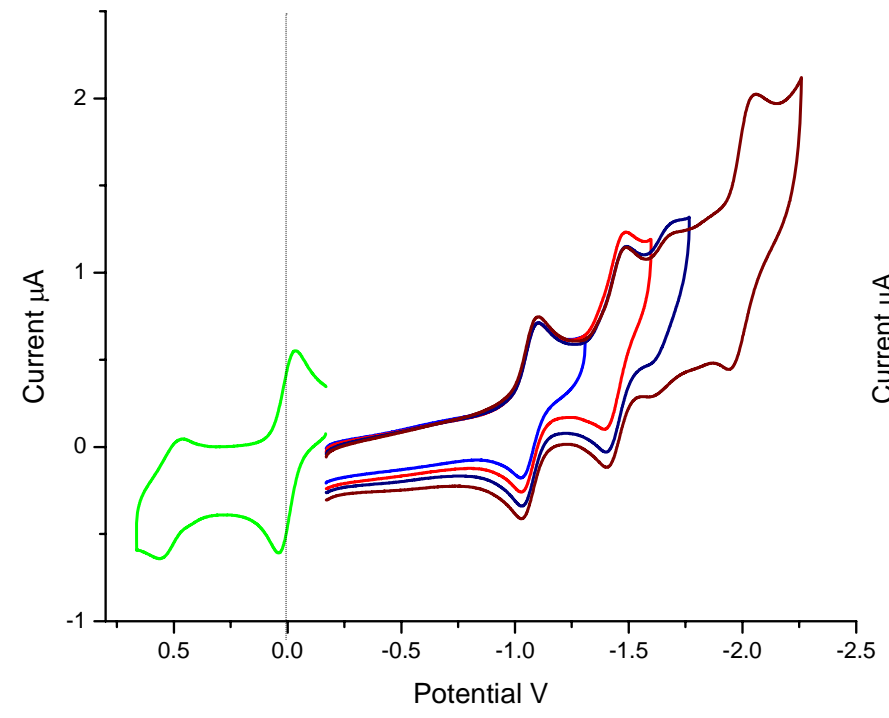

Figure S3.

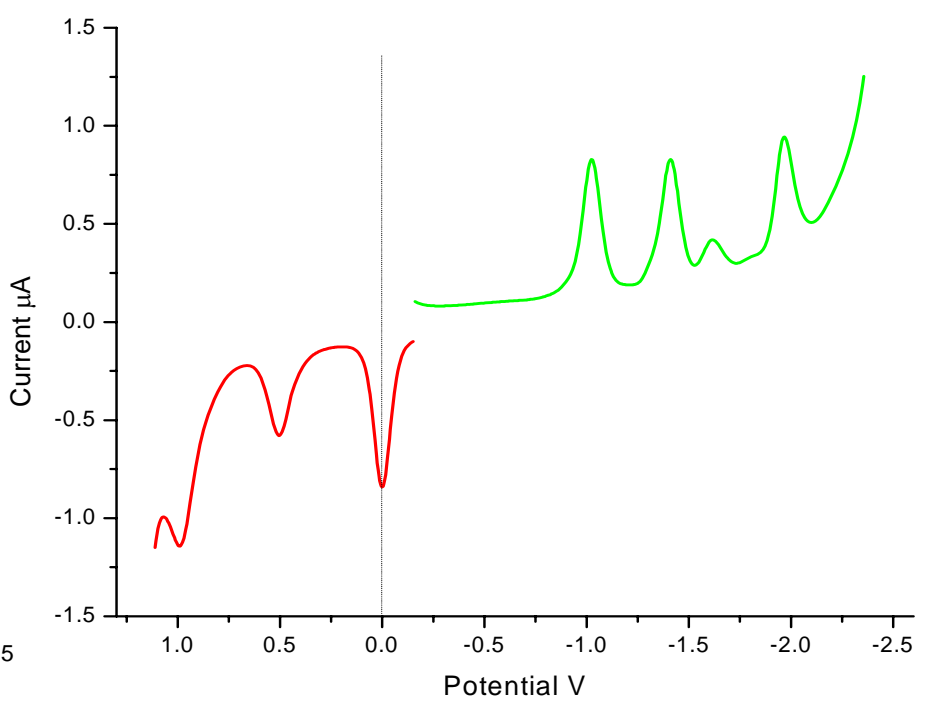

Figure S4.

Figure S3. Cyclic voltammogram (CV) of compound $\mathbf{4 b}$

Figure S4. Differential Pulse Voltammetry (DPV) of compound 4b 


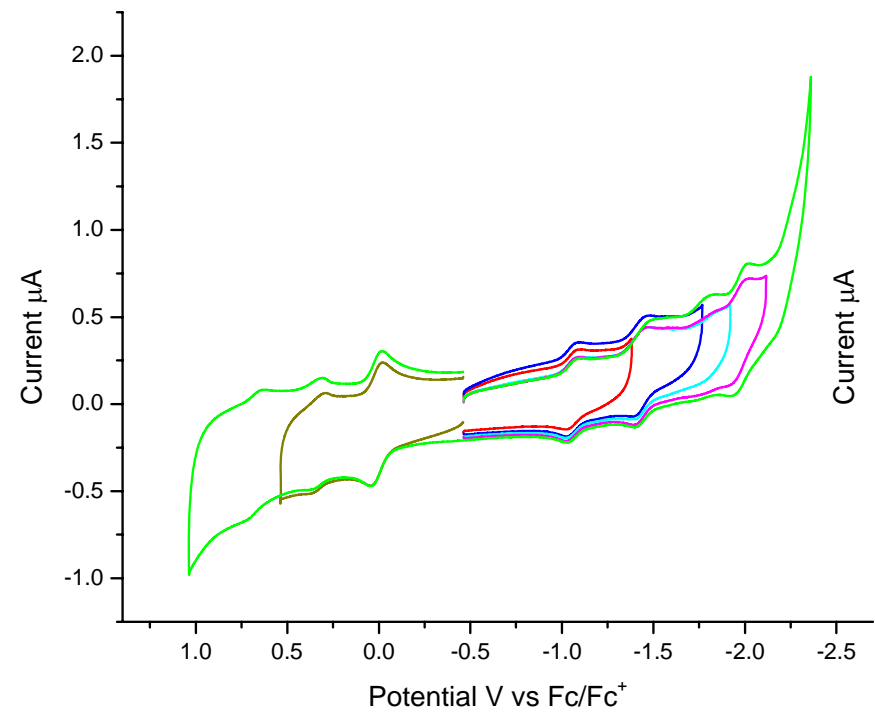

Figure S5.

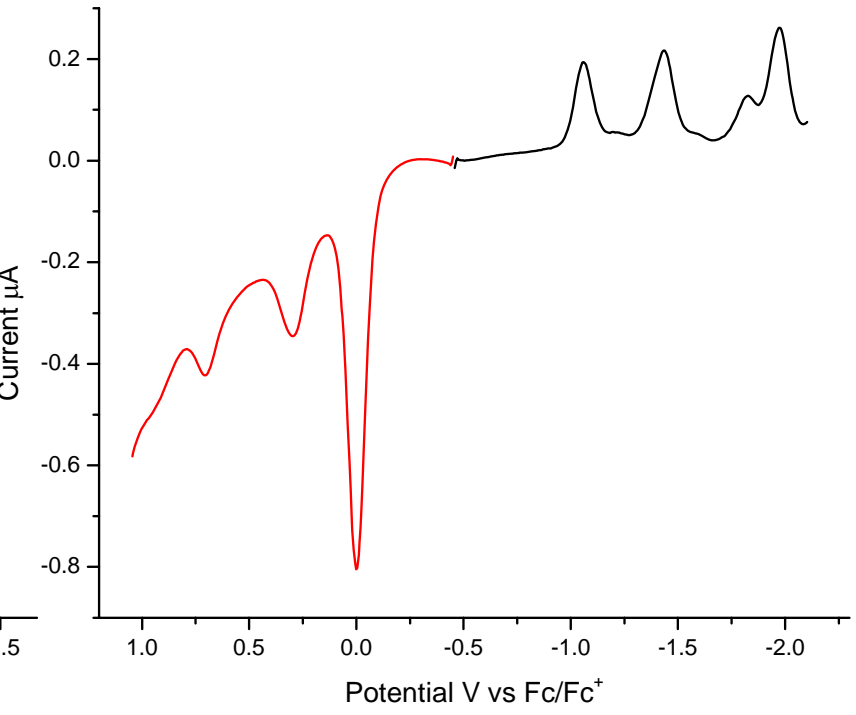

Figure S6.

Figure S5. Cyclic voltammogram (CV) of compound 5b

Figure S6. Differential Pulse Voltammetry (DPV) of compound 5b 


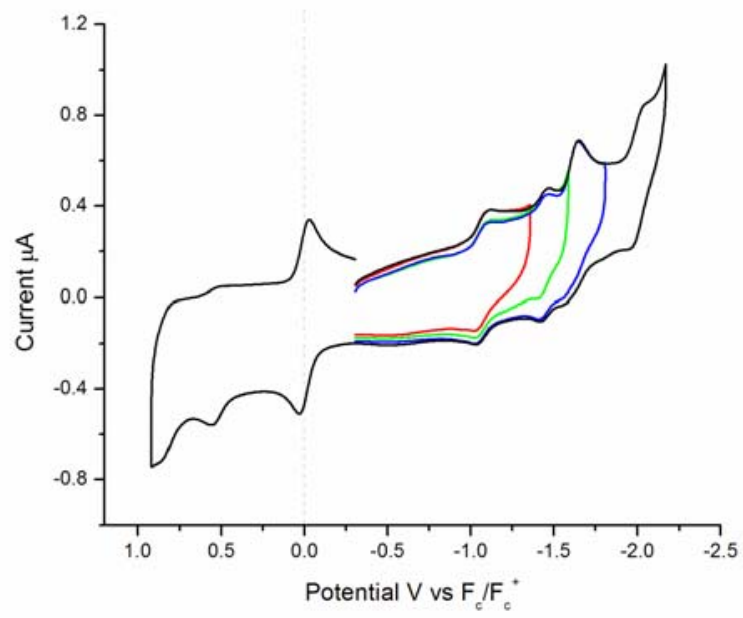

Figure S7. Cyclic voltammogram of $\mathbf{4 a}$

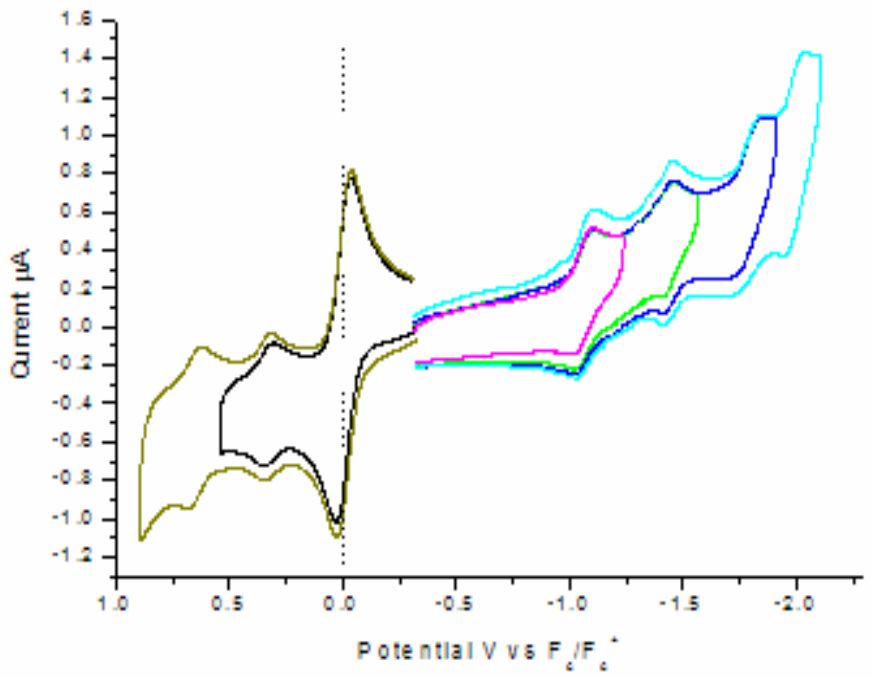

Figure S8. Cyclic voltammogram of $\mathbf{5 a}$ 


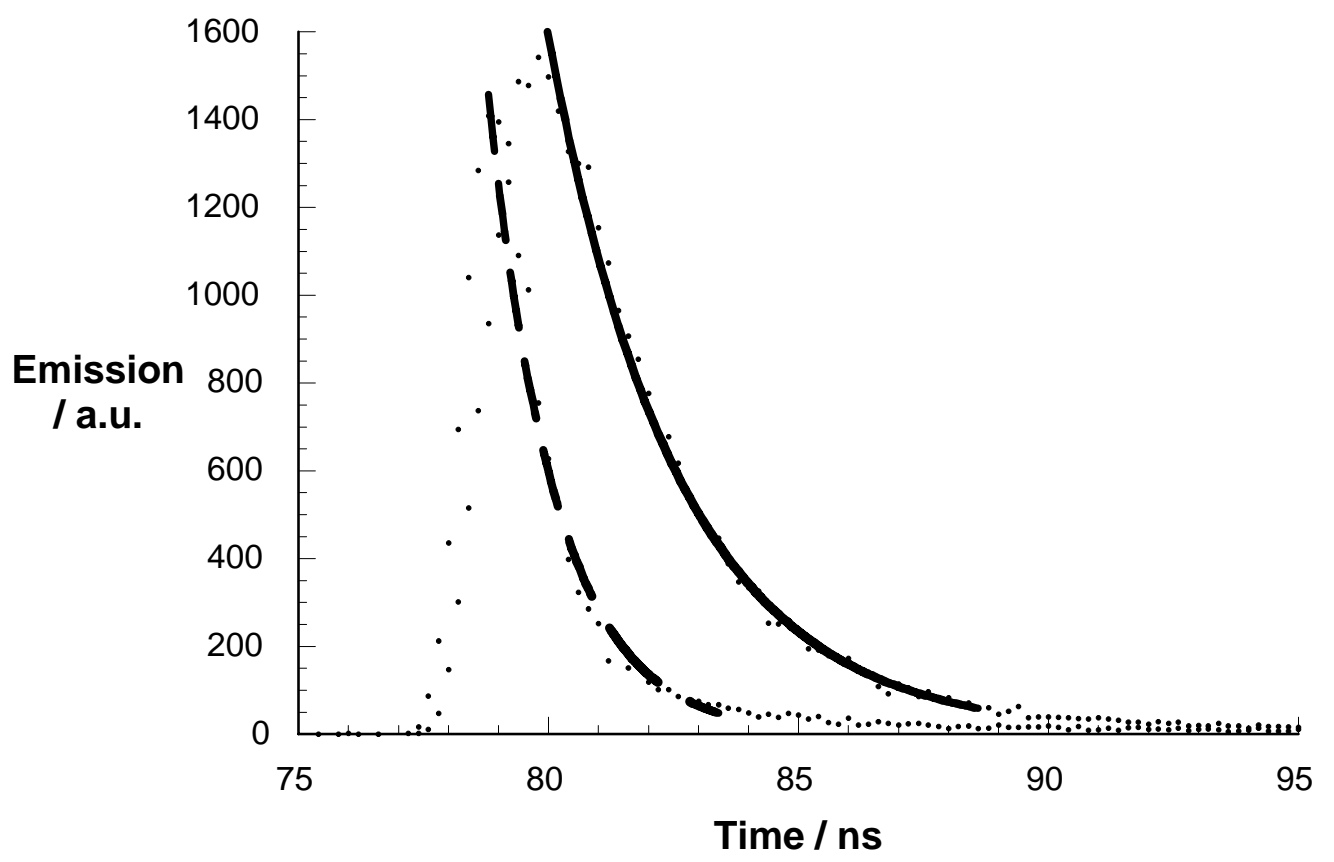

Figure S9. Time-resolved fluorescence decay of the ZnP reference (solid monitored at $610 \mathrm{~nm}$ ) and $\mathrm{Me}-\mathrm{H}_{2} \mathrm{P}-\mathrm{C}_{60} \mathbf{4 a}$ (dashed - monitored at $650 \mathrm{~nm}$ ) in aerated toluene following $337 \mathrm{~nm}$ laser excitation of the porphyrin moiety. 

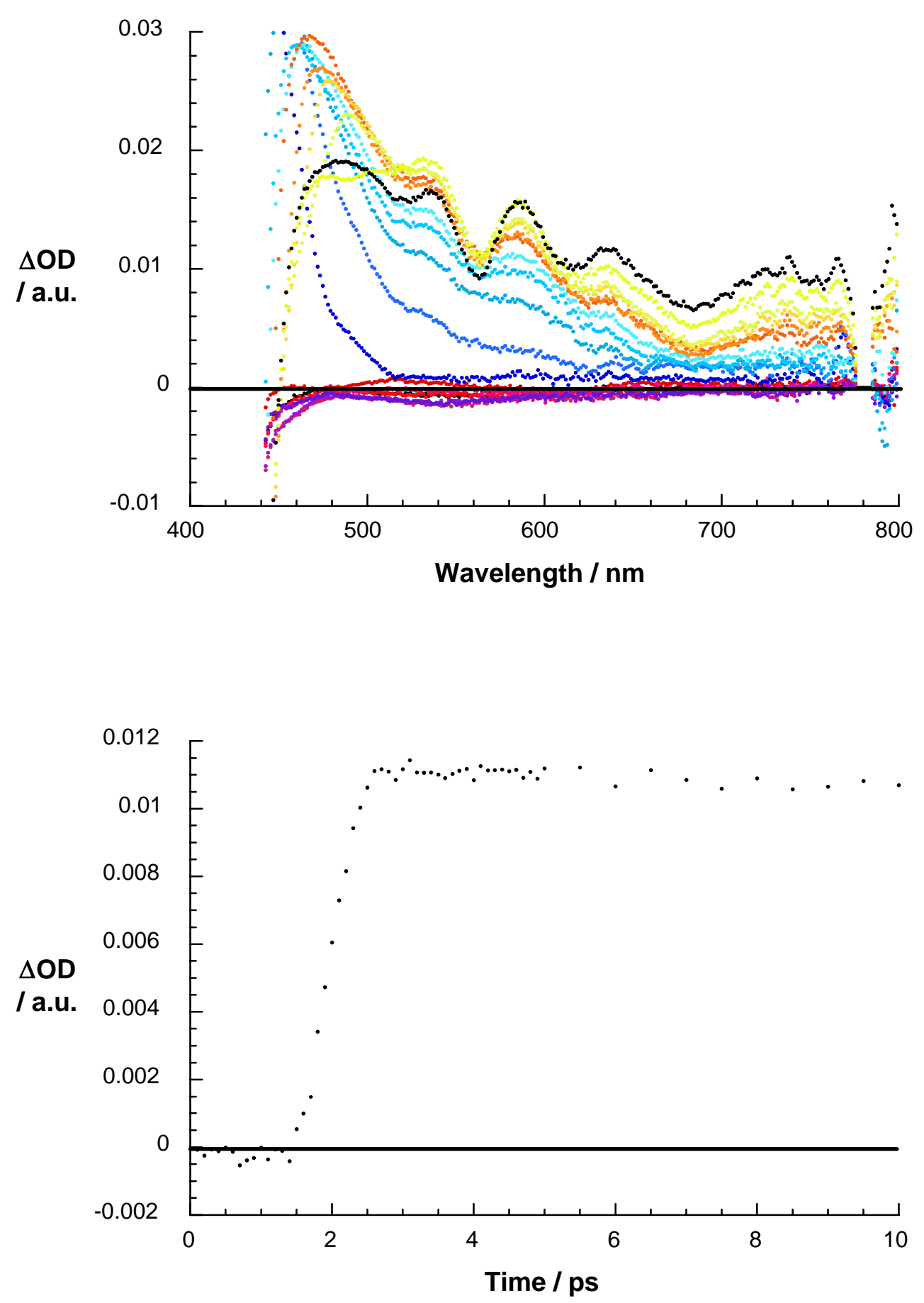

Figure S10: Upper part - differential absorption spectrum (visible) obtained upon femtosecond flash photolysis (387 nm) of ZnP in nitrogen-saturated benzonitrile with several time delays between 0 and $10 \mathrm{ps}$ at room temperature. Lower part time-absorption profiles of the spectra shown above at $750 \mathrm{~nm}$, monitoring the formation of the porphyrin singlet excited state of $\mathrm{ZnP}$ in benzonitrile. 

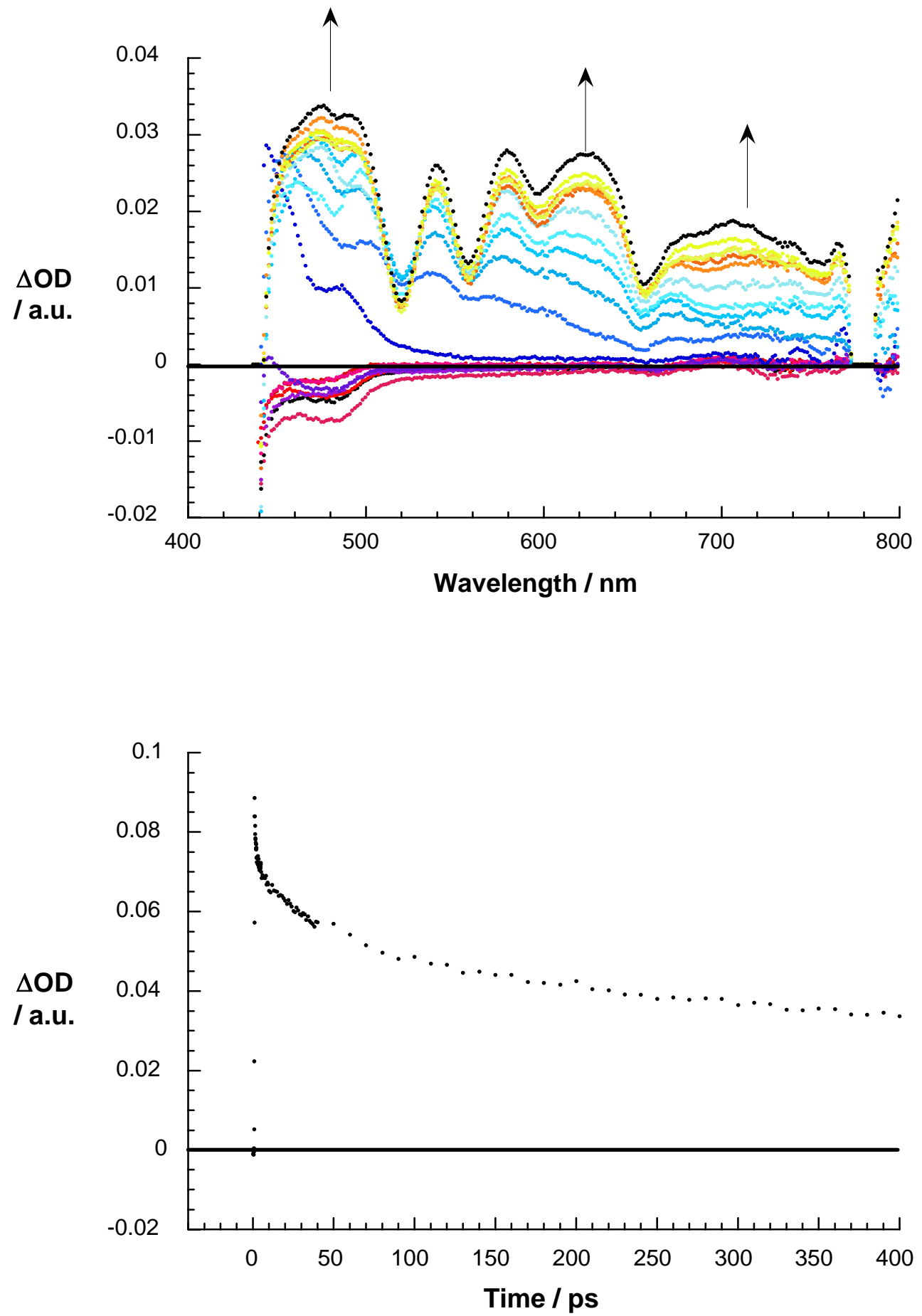

Figure S11: Upper part - differential absorption spectrum (visible) obtained upon femtosecond flash photolysis $\left(387 \mathrm{~nm}\right.$ ) of $\mathrm{Me}^{-} \mathrm{H}_{2} \mathrm{P}-\mathrm{C}_{60}$ 4a in nitrogen saturated benzonitrile with several time delays between 0 and $400 \mathrm{ps}$ at room temperature. Lower part - time-absorption profile of the absorption at $420 \mathrm{~nm}$, monitoring the transformation of the singlet excited to the radical ion pair state. 

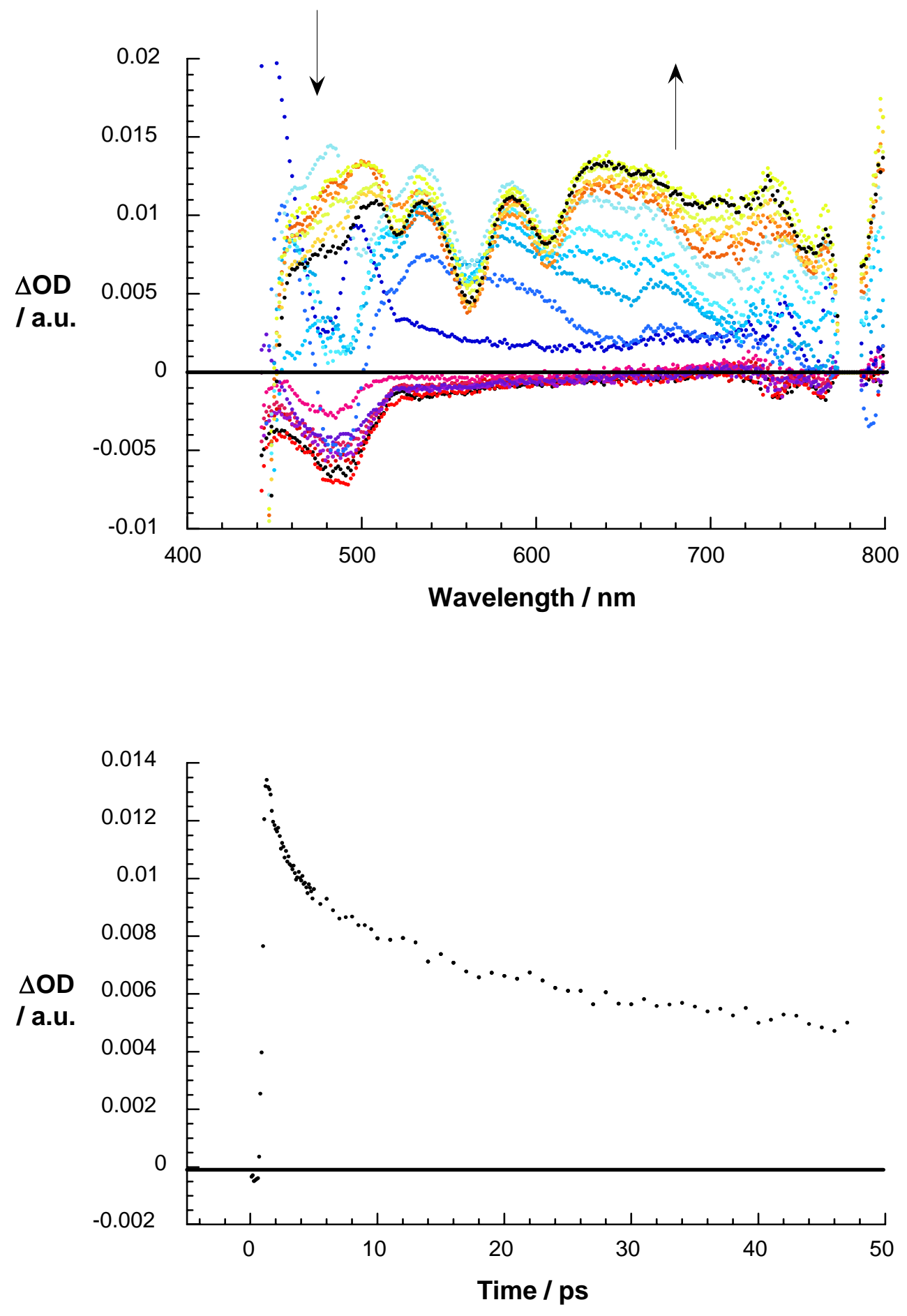

Figure S12: Upper part - differential absorption spectrum (visible) obtained upon femtosecond flash photolysis $(387 \mathrm{~nm}$ ) of Me-ZnP-C 60 5a in nitrogen saturated benzonitrile with several time delays between 0 and 50 ps at room temperature. Lower part - time-absorption profiles of the absorption at $480 \mathrm{~nm}$, monitoring the transformation of the singlet excited to the radical ion pair state. 


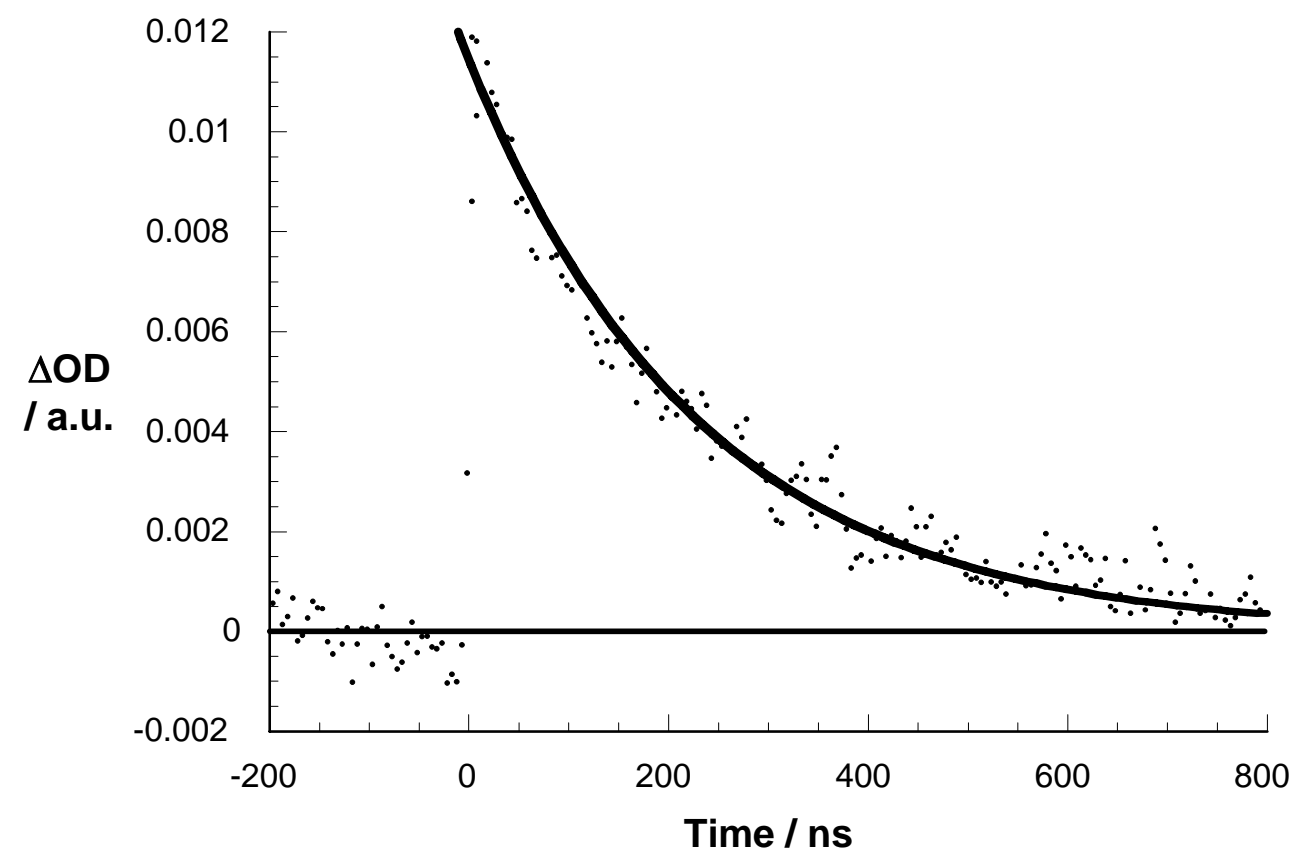

Figure S13: Time-absorption profile at $1000 \mathrm{~nm}$ monitoring the $\mathrm{C}_{60}{ }^{--}$decay dynamics of $\mathrm{t}_{\mathrm{Bu}}-\mathrm{ZnP}^{*+}-\mathrm{C}_{60}{ }^{-} \mathbf{5 b}$ produced upon $532 \mathrm{~nm}$ excitation in nitrogen saturated THF. 


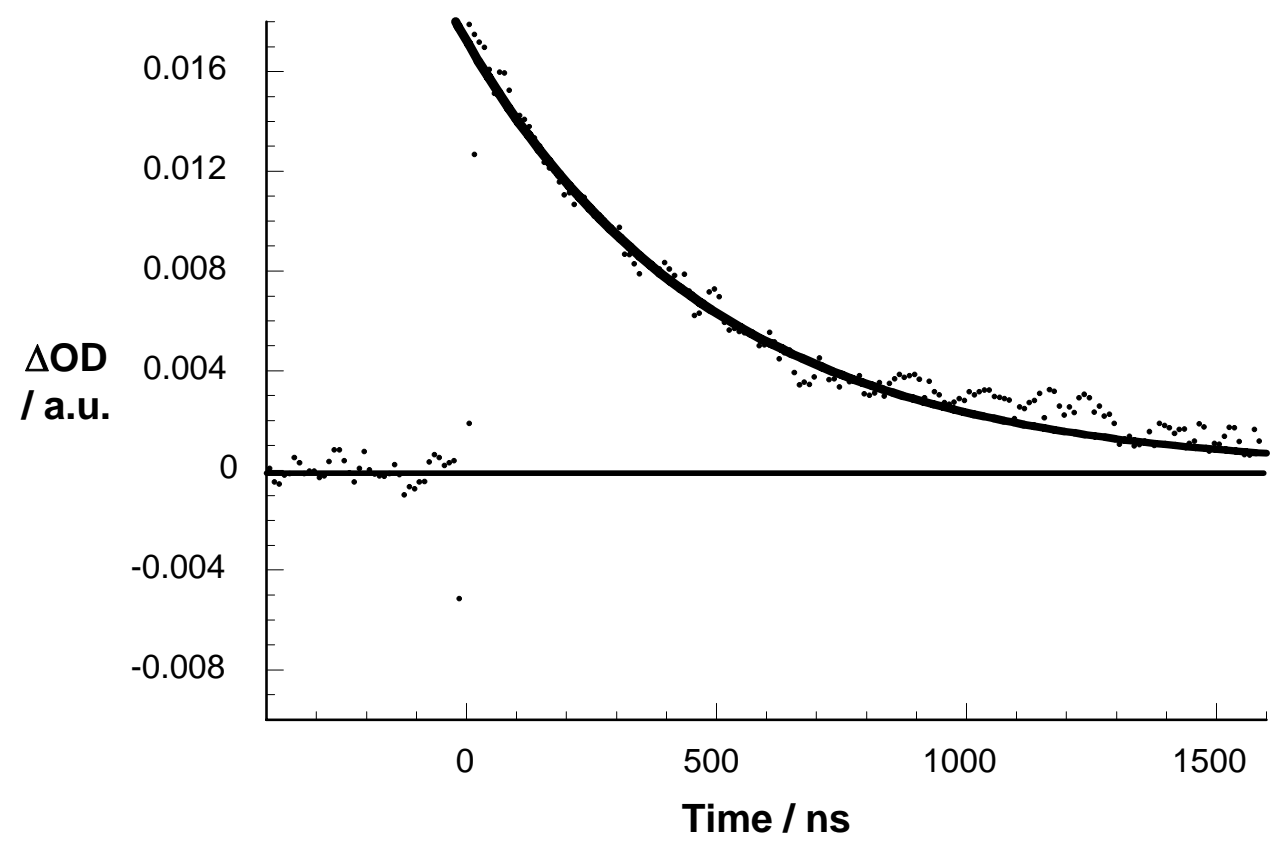

Figure S14: Time-absorption profile at $1000 \mathrm{~nm}$ monitoring the $\mathrm{C}_{60}{ }^{-}$decay dynamics of $\mathrm{Me}-\mathrm{H}_{2} \mathrm{P}^{\circ+}-\mathrm{C}_{60}{ }^{--}$4a produced upon $532 \mathrm{~nm}$ excitation in nitrogen saturated THF. 
H2MeAZA (4a) in PhCN at $620 \mathrm{~nm}$, lifetiems 25 and 600 ps

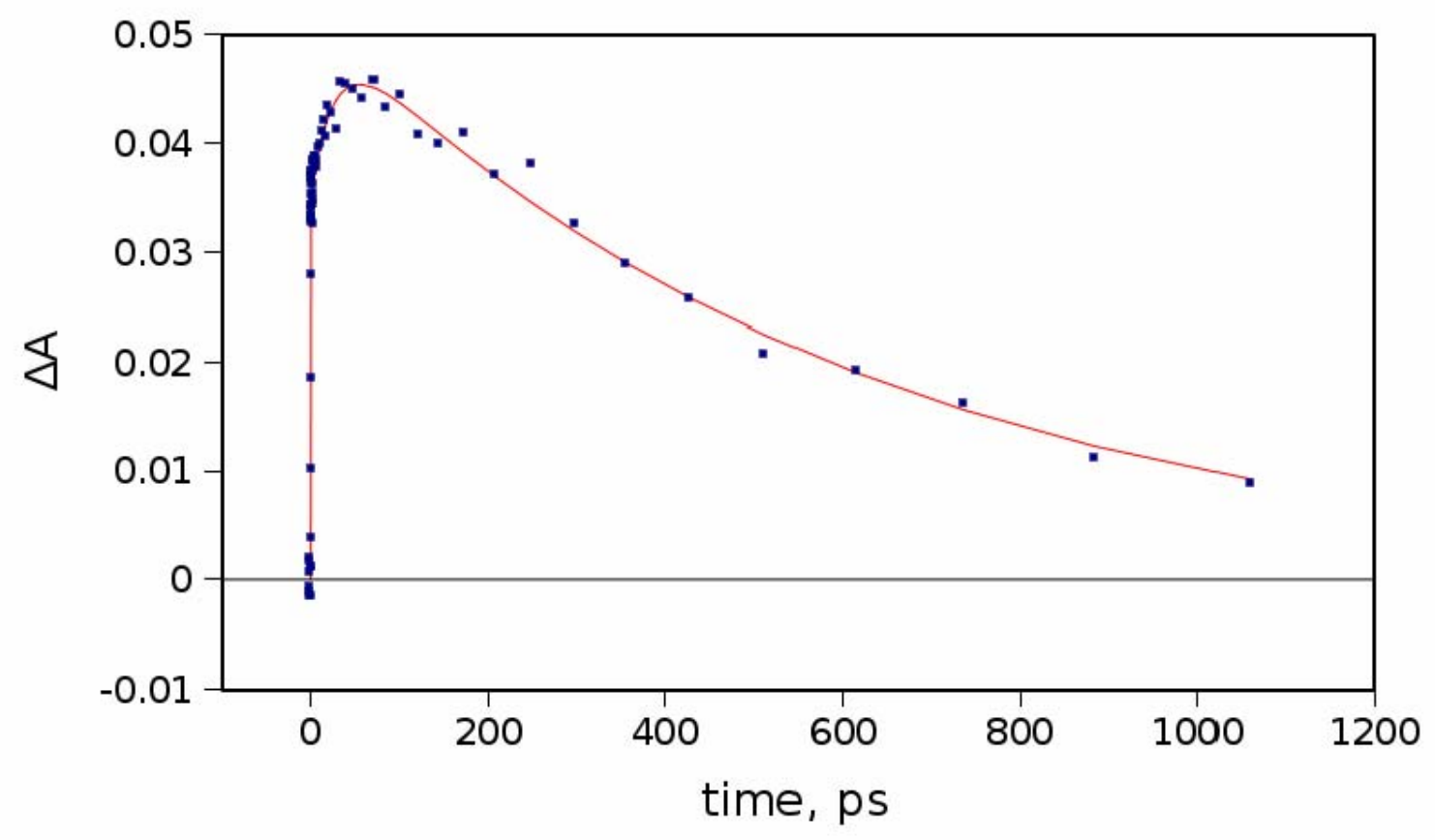

Figure S15. Pump-probe study of dyad 4a in benzonitrile. Excitation at $413 \mathrm{~nm}$, monitoring wavelength $620 \mathrm{~nm}$. 
H2BuAZA (4b) in PhCN at $620 \mathrm{~nm}$, lifetimes $13 \mathrm{ps}$ and $1 \mathrm{~ns}$

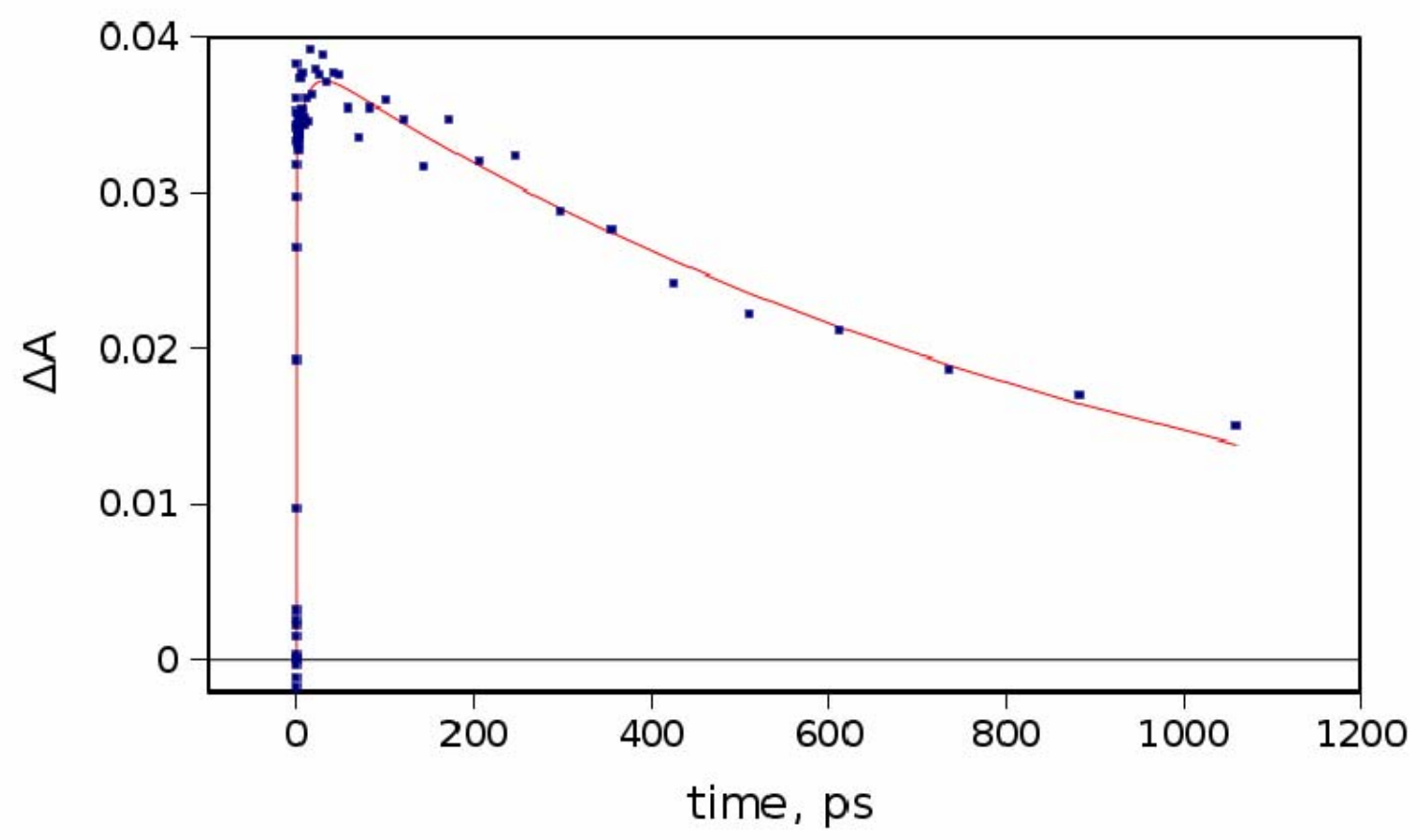

Figure S16. Pump-probe study of dyad $\mathbf{4 b}$ in benzonitrile. Excitation at $413 \mathrm{~nm}$, monitoring wavelength $620 \mathrm{~nm}$. 


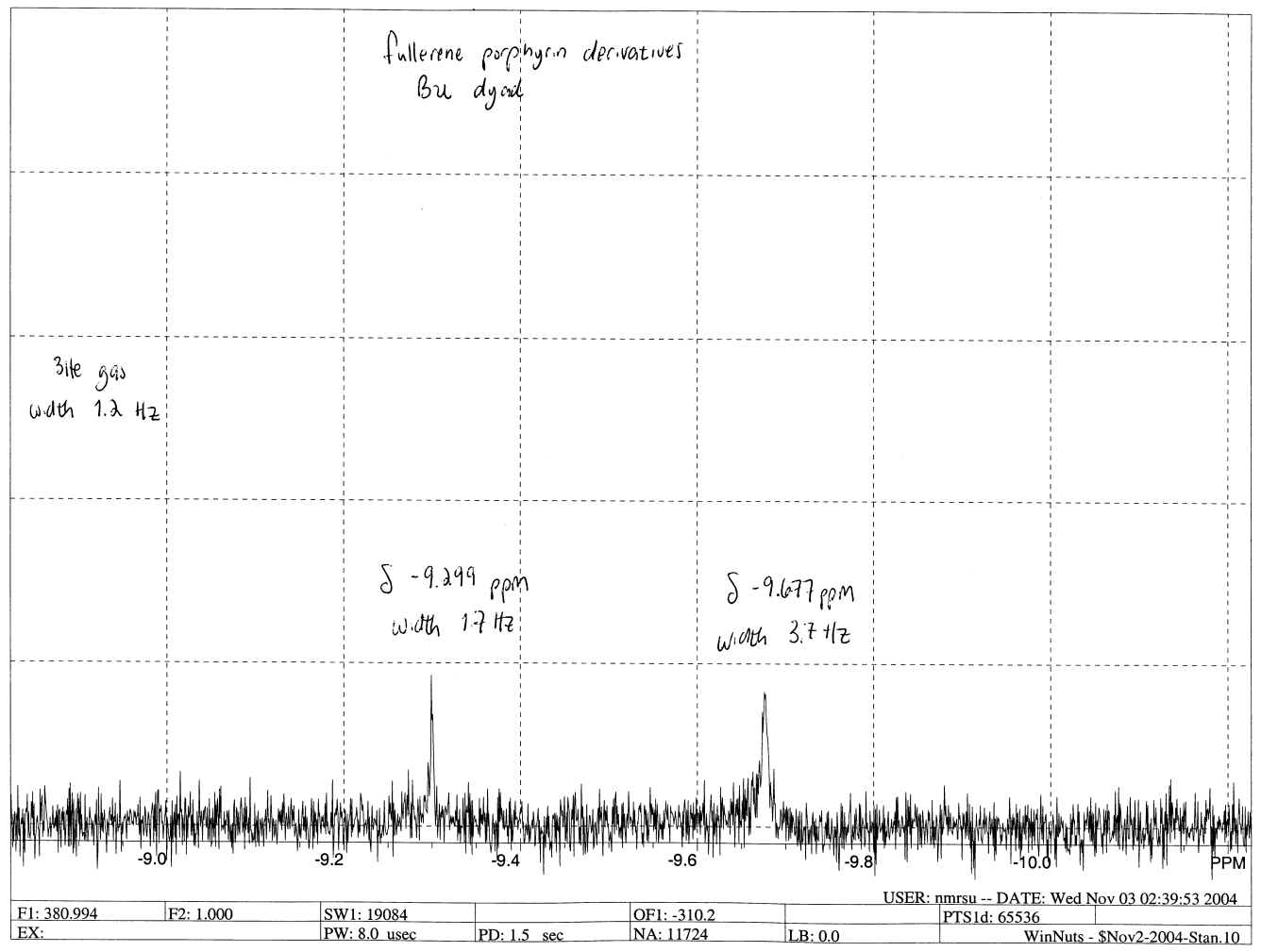

Figure S17. ${ }^{3} \mathrm{He}$ NMR spectrum of tert-Bu-dyad $\mathbf{4 b}$ 


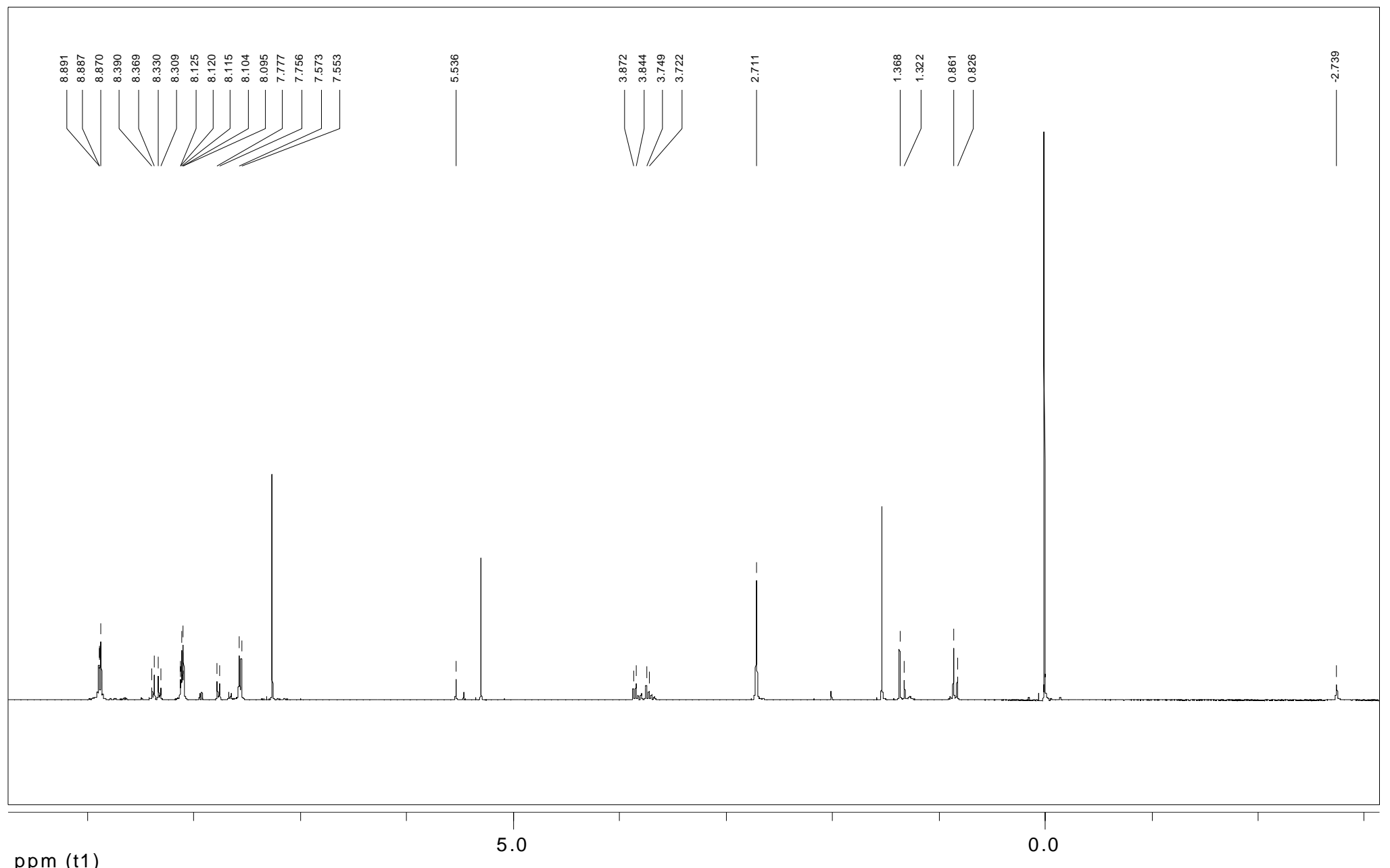

Figure S18. ${ }^{1} \mathrm{H}$ NMR spectrum of $3 a\left(\mathrm{R}=\mathrm{R}_{1}\right)$ 


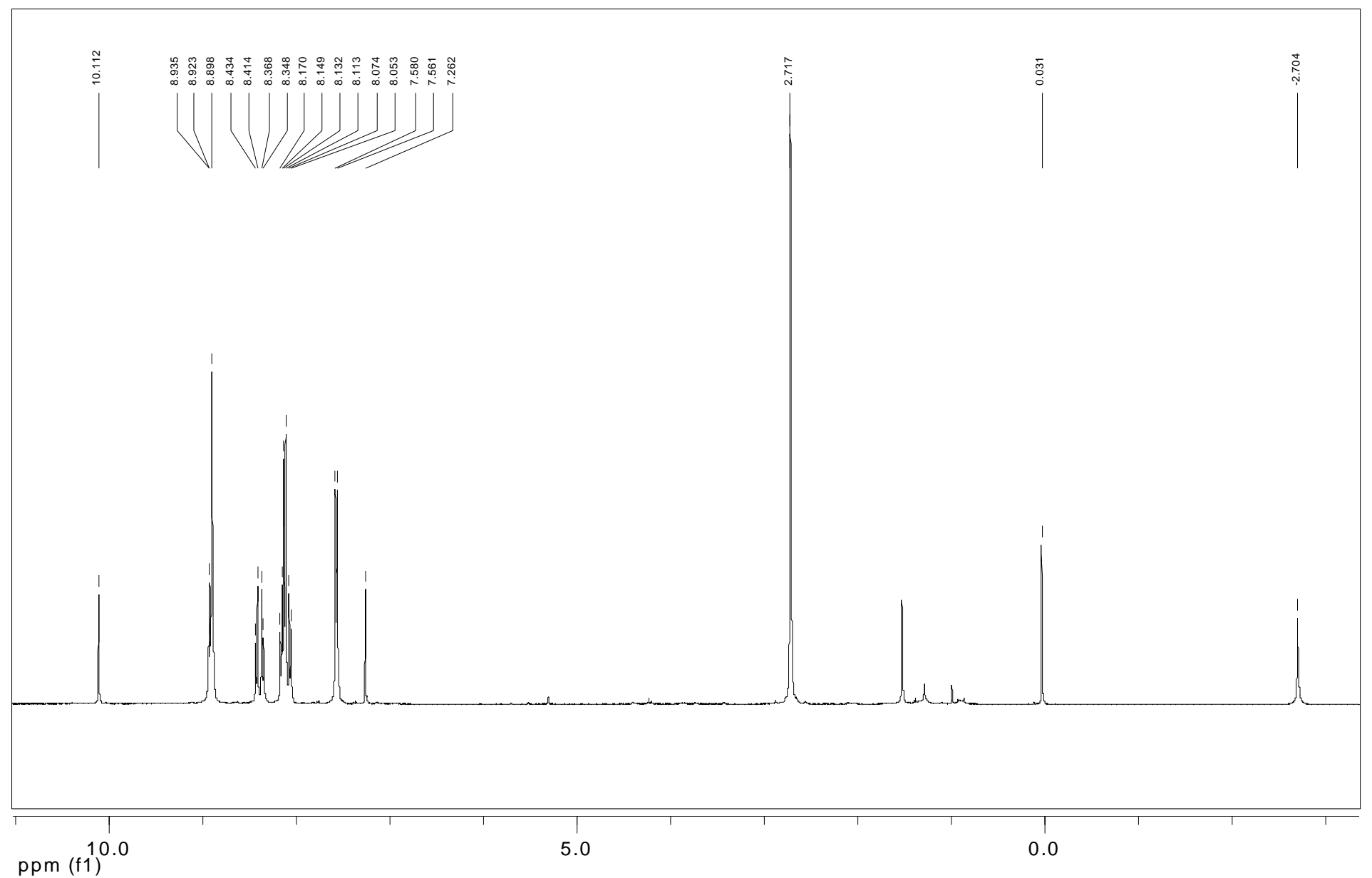

Figure S19. ${ }^{1} \mathrm{H}$ NMR spectrum of 3 a. 


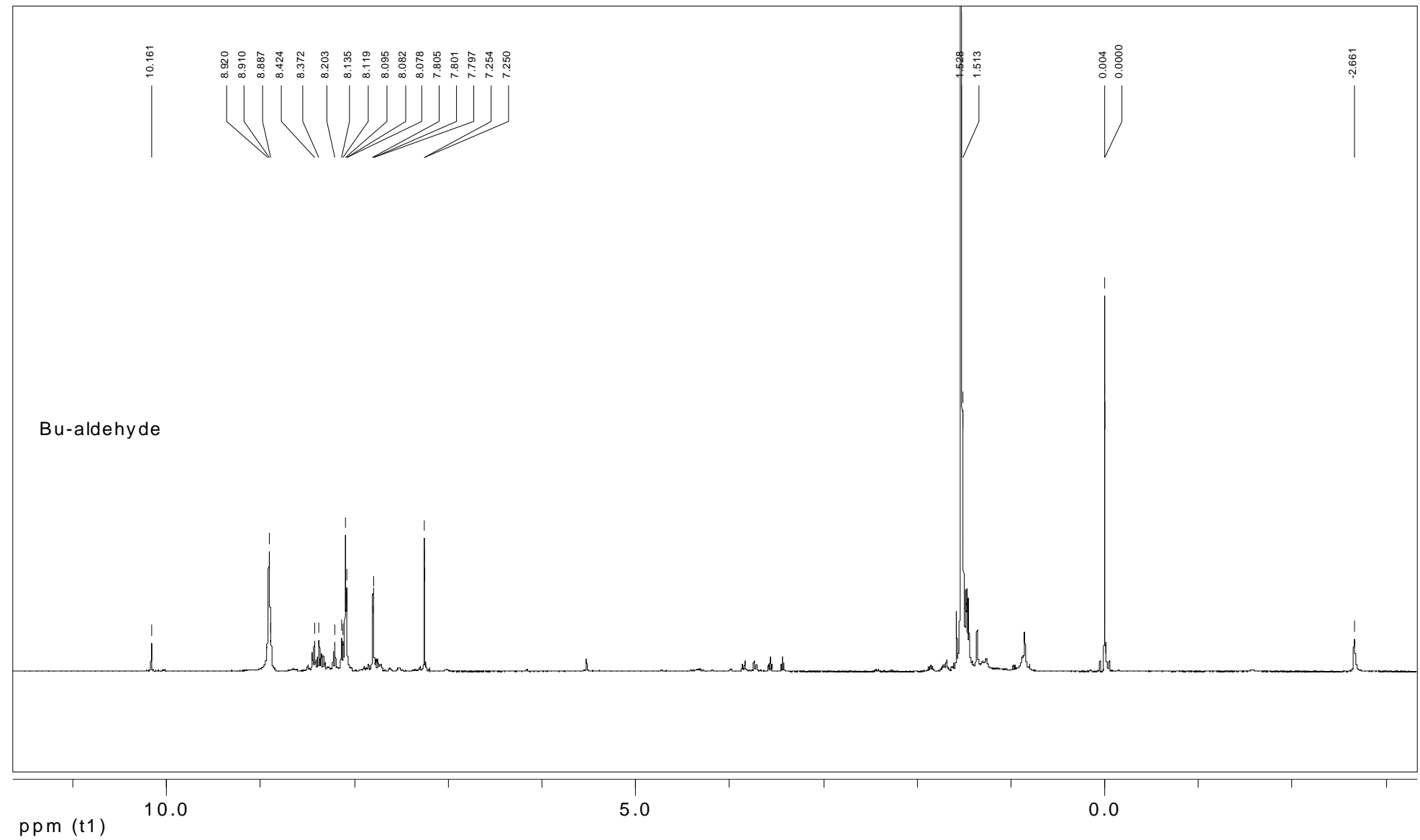

Figure S20. ${ }^{1} \mathrm{H}$ NMR spectrum of $\mathbf{3 b}$. 


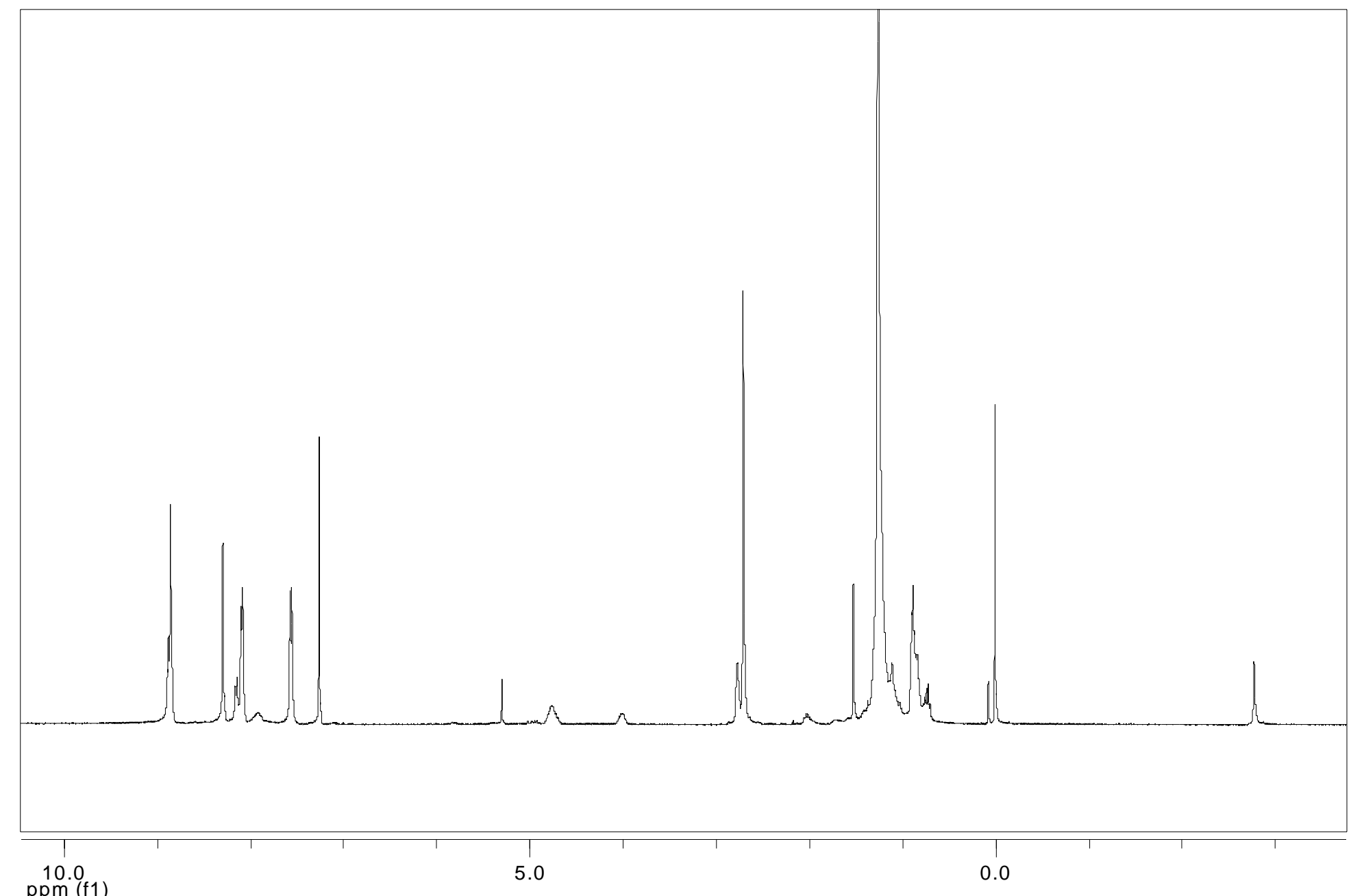

$\mathrm{ppm}(\mathrm{f} 1)$

Figure S21. ${ }^{1} \mathrm{H}$ NMR spectrum of $\mathbf{4 a}$. 


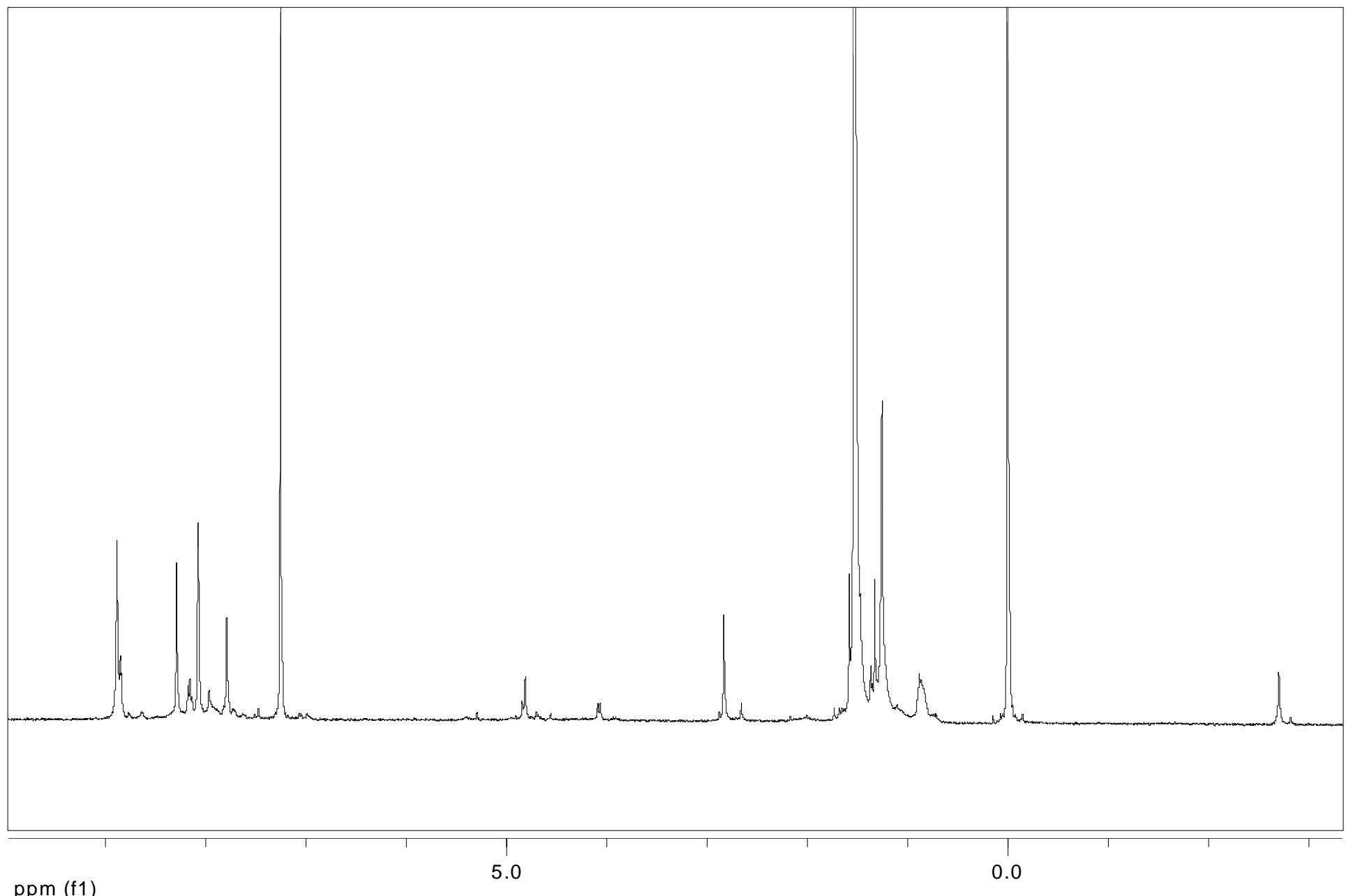

Figure S22. ${ }^{1} \mathrm{H}$ NMR spectrum of $\mathbf{4 b}$. 


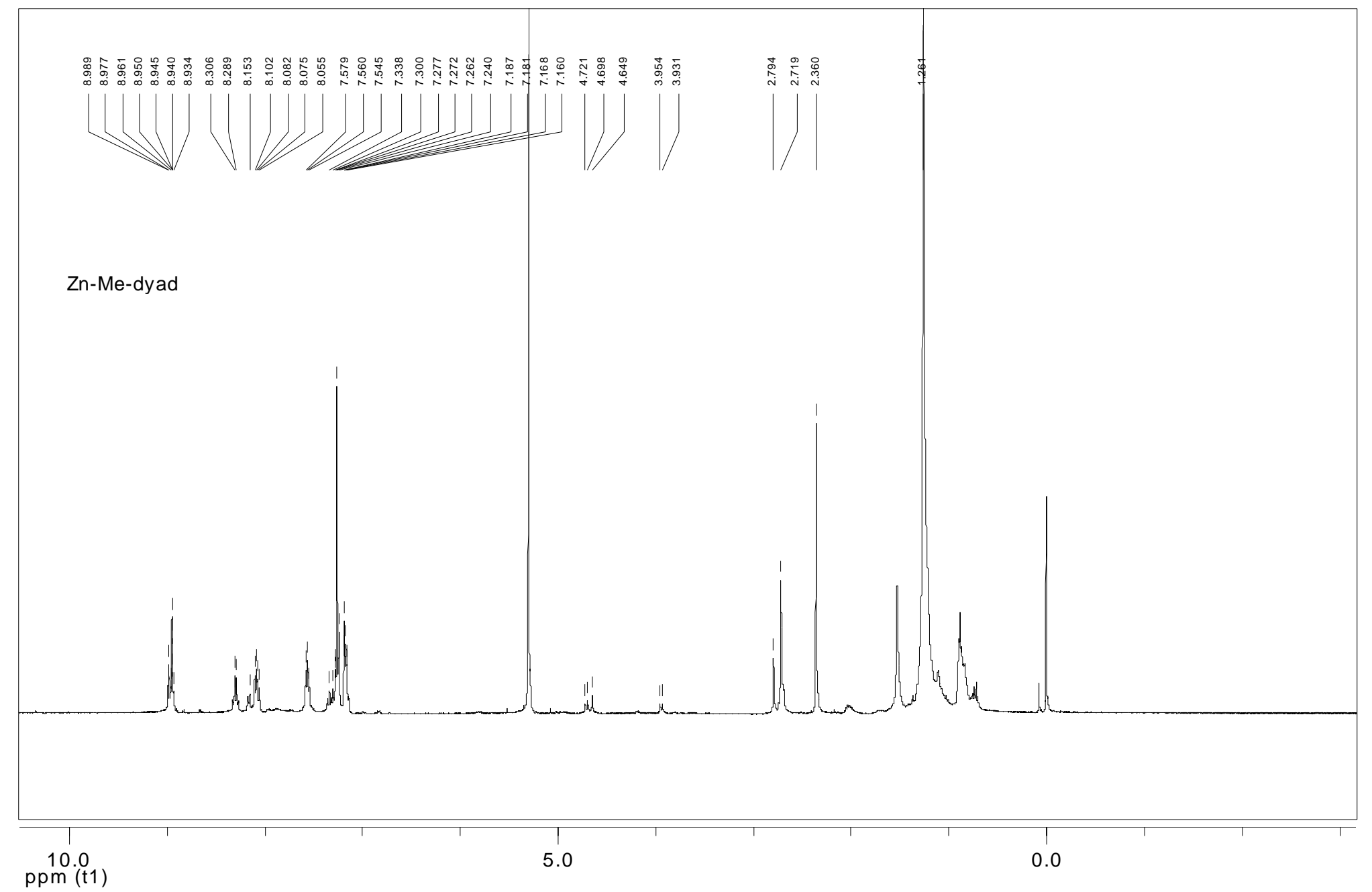

Figure S23. ${ }^{1}$ H NMR spectrum of 5 a. 


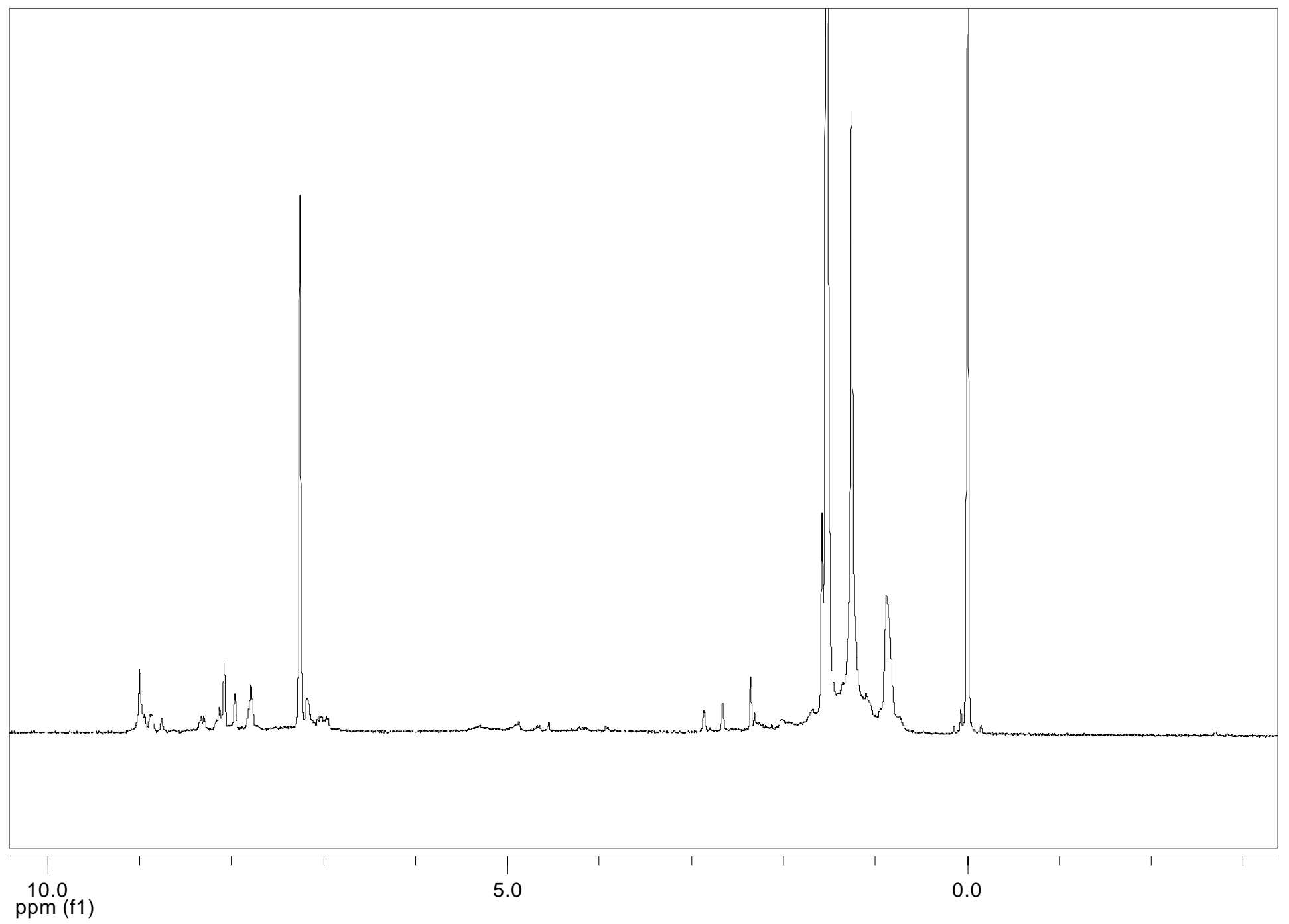

Figure S24. ${ }^{1} \mathrm{H}$ NMR spectrum of $\mathbf{5 b}$. 